Snake venoms have been used as antineoplastic substances in several experimental models. We demonstrated in previous studies that Botbrops jararaca venom (BjV) induces inhibition of Ehrlich ascites tumor (EAT) growth accompanied by an increase of mononuclear (MN) leukocytes in all groups inoculated with EAT and/or venom. The objective of the present study was to characterize the subpopulations of MN leukocytes involved in the inhibition of EAT growth by treatment with $\mathrm{BjV}$. Swiss mice were inoculated with $1.0 \times 10^{3}$ EAT cells by the intraperitoneal route and treated with $0.4 \mathrm{mg} / \mathrm{kg}$ of $\mathrm{BjV}$ by the same route (Group TV). Treatment was started $24 \mathrm{~h}$ after tumor cell inoculation and consisted of five intraperitoneal injections performed at $72 \mathrm{~h}$ intervals. After 2, 8 and 14 days, groups of animals were sacrificed and the number of $B$, TCD4 and TCD8 lymphocytes, macrophages and natural killer cells present in the peritoneal cavity was determined by flow cytometry. The control group consisted of animals inoculated with EAT and treated with $0.1 \mathrm{ml}$ of saline under the same conditions as the experimental group (Group T). Two additional control groups consisted of animals not inoculated with EAT and treated with saline or venom. Data were analyzed statistically by the Kruskal-Wallis nonparametric test for independent samples. On the 2nd and 8th day we observed a difference between groups $T$ and TV (group $T>$ group TV) for all cell types, except natural killer cells, that only differed on the 2nd day. However, on the 14th day there was no difference in MN cells among groups. These data suggest that the inhibition of EAT is related to the toxic action of $\mathrm{BjV}$ on tumor cells and/or to the proteolytic effect of the venom on the mediators produced by the cells for growth modulation.

Key words: Mononuclear leukocytes, Ehrlich ascites tumor, Venom, Bothrops jararaca

\section{Subpopulations of mononuclear leukocytes associated with inhibition of Ehrlich ascites tumor growth by treatment with Bothrops jararaca venom}

\author{
Mariana Morena de Vieira Santos ${ }^{1}$, \\ Reinaldo José da Silva ${ }^{2}$, Márcia Guimarães da \\ Silva ${ }^{1}$ and Denise Fecchio ${ }^{\mathrm{CA}, 1}$
}

${ }^{1}$ Departamento de Patologia, Faculdade de Medicina de Botucatu, and ${ }^{2}$ Departamento de Parasitologia, Instituto de Biociências, UNESP, Botucatu, São Paulo CEP 18618-000, Brazil

\author{
${ }^{\mathrm{CA}}$ Corresponding author \\ Tel: +551438116146 \\ E-mail: dfecchio@fmb.unesp.br
}

\section{Introduction}

Snake venoms have been used as antitumor substances in several experimental protocols. ${ }^{1}$ In previous studies we demonstrated that the venom of Crotalus durissus terrificus and Bothrops jararaca venom $(\mathrm{BjV})$ have an important inhibitory effect on the growth of Ehrlich ascites tumor (EAT). ${ }^{2,3}$

The inhibition of EAT growth in the animals treated with $\mathrm{BjV}$ is accompanied by alteration in the cytokine profile in the peritoneal cavity of the animals ${ }^{4}$ and by an increase of mononuclear (MN) leukocytes in all groups inoculated with EAT and/or venom. ${ }^{3}$ Although no difference was detected in the increased quantity of MN cells in the peritoneal cavity of these groups, we do not rule out the possibility that different subpopulations may be involved in tumor growth inhibition.
There are no reports in the literature that demonstrate the cell types involved in the inhibition of EAT growth. This aspect is important because it will allow one to infer whether the inhibition of the tumor growth is associated with a certain cell population and/or with the direct effect of the venom on these cells. The aim of the present study was determine the cell subpopulation involved in EAT growth inhibition after treatment with $\mathrm{Bj}$.

\section{Materials and methods}

\section{Animals}

Male Swiss male mice, 4-6 weeks old, from our own animal facilities were used throughout the experiment. 


\section{Venoms}

$\mathrm{BjV}$ was obtained from snakes maintained in captivity at The Center for the Study of Venoms and Venomous Animals of São Paulo State University, Brazil. Newly extracted venom was centrifuged for $10 \mathrm{~min}$ at 200 $\times$ g, filtered through a GSWP00250 Millipore filter, and lyophilized. The lethal dose $50\left(\mathrm{LD}_{50}\right)$ for this venom was previously determined as $2.4 \mathrm{mg} / \mathrm{kg}$ of animal weight. The venom was stored at $4{ }^{\circ} \mathrm{C}$ during the experiment. Preliminary protocols have shown that $0.4 \mathrm{mg} / \mathrm{kg}$ of $\mathrm{BjV}$ is effective for tumor growth inhibition.

\section{Ehrlich ascites tumor}

The tumor was maintained in Swiss mice in the ascitic form. Tumor cells were collected by aspiration with a Pasteur pipette, centrifuged for $10 \mathrm{~min}$ at $200 \times g$, and washed twice with phosphate-buffered saline (pH 7.2). Cell viability was evaluated by the Trypan blue exclusion test, and only cell suspensions that presented more than 95\% viability were used.

\section{Peritoneal cells}

Cells were harvested by peritoneal washing using 3 $\mathrm{ml}$ of sterile phosphate-buffered saline. The number of cells was determined with a hemocytometer. Differential counts were performed on fixed and stained cell suspensions ( $0.5 \%$ crystal violet dissolved in $30 \%$ acetic acid).

\section{Analysis of the MN leukocyte subpopulations by flow cytometry}

In this protocol we evaluated the number of five types of MN leukocytes: $\mathrm{TCD}_{4}, \mathrm{TCD}_{8}$ and $\mathrm{B}$ lymphocytes (CD22), macrophages (Mac3), and natural killer (NK1.1) cells. The total number of cells present in the peritoneal cavity was determined with a hemocytometer and the number of MN leukocytes was determined by flow cytometry. The peritoneal suspensions were adjusted to $1 \times 10^{6}$ cells $/ \mathrm{ml}$, and 100 $\mu \mathrm{l}$ of this solution were incubated with a monoclonal antibody labeled with fluorescein isothiocyanate (FITC). The protocols, antibodies and reagents employed were as per the manufacturer's recommendations (Pharmigen). The percentage of labeled cells was obtained by analysis of 10,000 cells/sample with a FACSCalibur flow cytometer (Becton-Dickinson, Palo Alto, CA, USA) using the Cell-Quest software.

\section{Experiment design}

Mice were inoculated by the intraperitoneal route (i.p.) with $1 \times 10^{3}$ EAT cells and treated with $\mathrm{BjV}(0.4$ $\mathrm{mg} / \mathrm{kg}$ ) or saline $(0.1 \mathrm{ml}$, i.p.). The first $\mathrm{BjV}$ dose was administered $24 \mathrm{~h}$ after tumor implantation and repeated five times at $72 \mathrm{~h}$ intervals. Additional non-tumor-bearing control groups were treated with $\mathrm{BjV}$ or saline according to the same protocol as used for the experimental groups. Ten animals from each group were sacrificed by sulfur ether inhalation 2, 8, and 14 days after EAT implantation, and the MN leukocyte number present in the peritoneal cavity was evaluated by flow cytometry.

\section{Statistical analysis}

Data were analyzed statistically by the KruskallWallis test or by analysis of variance for independent sets, and by the Tukey or Student-Newman-Keuls test for differences between groups, with the level of significance set at 5\%.

\section{Results}

Analysis of the results obtained on the 2nd and 8th day of tumor growth showed that the group inoculated with tumor and treated with $\mathrm{BjV}$ presented a smaller amount of TCD4, TCD8 and B lymphocytes, and of macrophages, compared with the group inoculated with EAT cells and not treated with venom. For natural killer cells, a decrease was observed only on the 2nd day. However, on the 14 th day the amounts of all cell types were similar in the groups inoculated with tumor, whether or not they were treated with venom (Table 1).

We also observed that the group not inoculated with EAT cells and treated with $\mathrm{BjV}$ showed a reduction in the number of TCD 4 lymphocyte, B lymphocyte, macrophage and tural killer cells on the 2nd day of tumor growth, an increase in TCD8 cells on the 8th day and an increase in macrophages on the 14th day compared the control group inoculated with saline (Table 1).

\section{Discussion}

The present study was carried out to characterize the cell subpopulation involved in the evolution of EAT treated with $\mathrm{BjV}$, because in a previous study we demonstrated that treatment with this venom induces an increase in MN leukocytes in all groups inoculated with EAT cells and/or venom compared with the saline control group. ${ }^{3}$ However, in this previous study, we did not detect a difference in the amount of MN leukocytes present in the peritoneal cavity peritoneal among the groups inoculated with tumor and/or venom. Nevertheless, we did not exclude the possibility that different subpopulations could be involved in the inhibition of tumor growth. The 


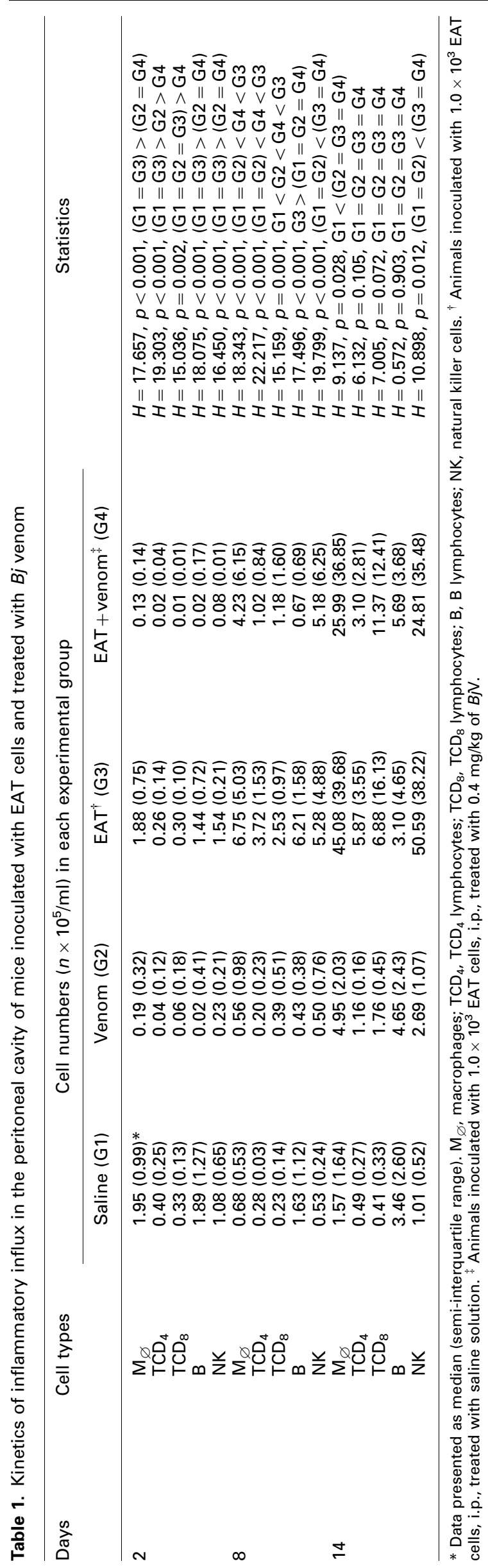

literature shows that MN leukocytes can have an effective participation in the elimination of tumor cells, ${ }^{5-13}$ and therefore it would be important to evaluate the participation of this cell type in the evolution of EAT.

However, analysis of the results obtained in this stage of the study showed that there was no difference in the amounts of TCD4 lymphocytes, TCD lymphocytes, B lymphocytes, macrophage and natural killer cells between the groups inoculated with tumor, treated or not with BjV. Thus, we believe that tumor growth inhibition is related to a direct effect of the poison on tumoral cells and/or for to the proteolytic effect of the venom on the mediators produced by the tumor cells for growth modulation. These data agree with the results reported by Rizzo and Tuchiya ${ }^{14}$ and Silva et al. ${ }^{3}$ who showed a toxic effect of $\mathrm{BjV}$ both on tumor cells and on peritoneal cells.

Analysis of the results obtained by evaluation of the MN leukocyte subpopulations during this stage of the study showed that, $24 \mathrm{~h}$ after the first venom inoculation (2nd day of tumor growth), the numbers of all cell types studied (i.e. TCD4 lymphocytes, TCD8 lymphocytes, B lymphocytes, macrophages and natural killer cells) were significantly reduced compared with the control group inoculated with saline, indicating a toxic effect of the venom on these cells.

The present results did not show an effective participation of $\mathrm{MN}$ cell in the process of tumor growth inhibition observed in the previous experiments. These results strongly suggest that this inhibition is related to the direct effect of the venom on tumor cells and/or to the proteolytic effect of the venom on the mediators produced by the tumor cells for growth modulation.

ACKNOWLEDGEMENTS. Financial support from Fundação de Amparo à Pesquisa do Estado de São Paulo (FAPESP).

\section{References}

1. Silva RJ, Fecchio D, Barraviera B. Antitumor effect of snake venoms. $J$ Venom Anim Toxins 1996; 2: 79-90.

2. Silva RJ, Fecchio D, Barraviera B. Effect of Crotalus durissus terrificus venom on the Ehrlich ascites tumor. J Venom Anim Toxins 1997; 3 $324-341$.

3. Silva RJ, Silva MG, Vilela LC, Fecchio D. Antitumor effect of Bothrops jararaca venom. Med Inflamm 2002; 11: 99-104.

4. Silva RJ, Silva MG, Vilela LC, Fecchio D. Cytokine profile of Ehrlich ascites tumor treated with Bothrops jararaca venom. Med Inflamm 2002; 11: 197-201.

5. Gallagher G, Stimson WH, Findlay J, Al-Azzawi F. Interleukin-6 enhances the induction of human lymphokine-activated killer cells. Cancer Immunol Immunother 1990; 31: 49-52.

6. Iho S, Shau H, Golub SH. Characteristics of interleukin- 6 enhanced lymphokine-activated killer cell function. Cell Immunol 1991; 135: 66-

7. Kitahara M, Kishimoto S, Hirano T, Kishimoto T, Okada M. The in vivo anti-tumor effect of human recombinant interleukin-6. Jpn J Cancer Res 1990; 81: $1032-1038$

8. Luger TA, Krutmann J, Kirnbauer R, et al. IFN-beta 2/IL-6 augments the activity of human natural killer cells. J Immunol 1989; 143: 1206-1209. 
9. Okada M, Kitahara M, Kishimoto S, Matsuda T, Hirano T, Kishimoto T. IL-6/BSF-2 functions as a killer helper factor in the in vitro induction of cytotoxic T cells. J Immunol 1988; 141: 1543-1549.

10. Russel SW, Doe WF, Cochrane CG. Number of macrophages and distributions of mitotic activity in regressing and progressing Moleney sarcomas. J Immunol 1976; 116: 164-166.

11. Russel SW, Doe WF, McIntosh AT. Functional characterization of a stable non-cytolytic stage of macrophage activation in tumors. J Exp Med 1997; 146: $1511-1520$.

12. Sezzi ML, Beleli L, Nista A. Peritoneal macrophages and neoplastic cells. I. Macrophages activity induced by heavily-irradiated or heated-killed cancer cells. Oncology 1972; 26: 529-539.
13. Smyth MJ, Ortaldo JR, Bere W, Yagita H, Okumura K, Young HA. IL-2 and IL- 6 synergize to augment the pore-forming protein gene expression and cytotoxic potential of human peripheral blood $\mathrm{T}$ cells. $J$ Immunol 1990; 145: 1159-1166.

14. Rizzo E, Tuchiya HN. Cytopathic effect by Bothrops jararaca venom on animal cell cultures. Ciênc Cult 1972; 24: 184-189.

Received 25 September 2003

Accepted 30 October 2003 


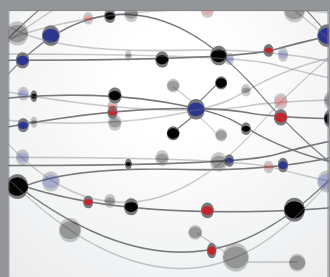

The Scientific World Journal
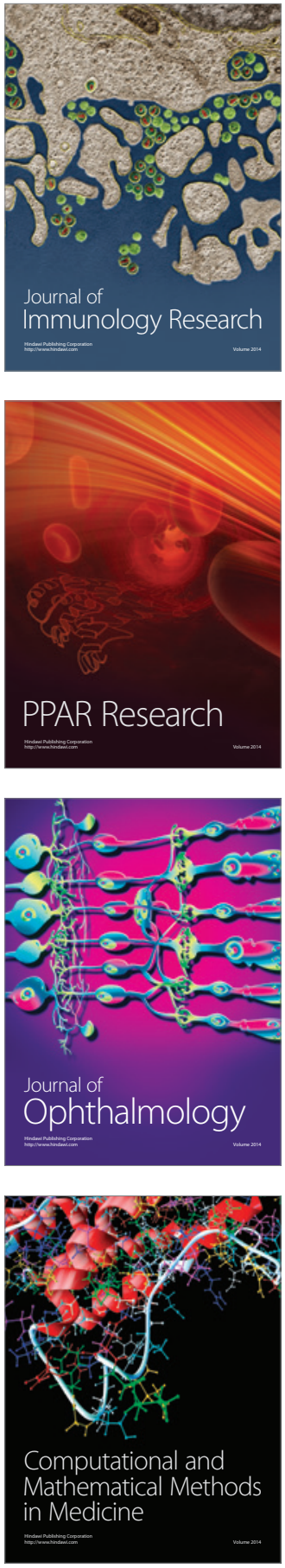

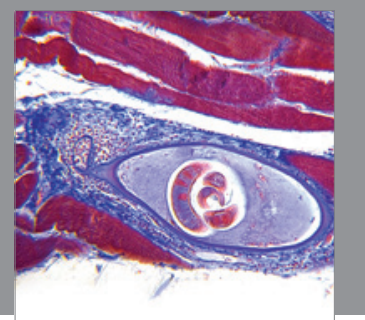

Gastroenterology

Research and Practice
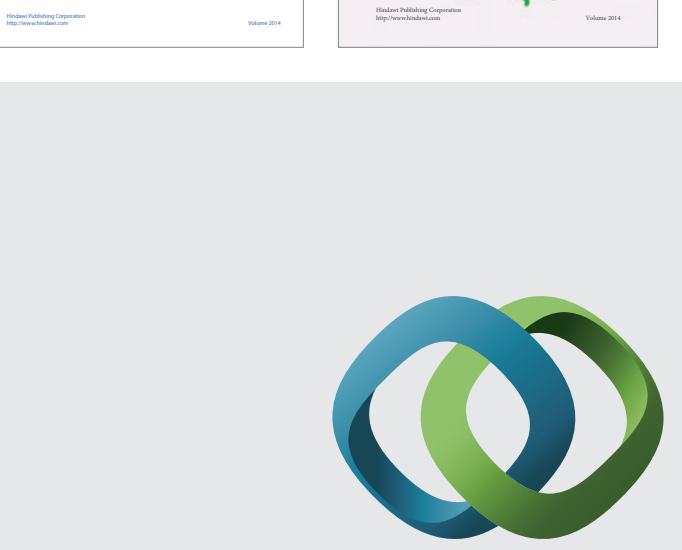

\section{Hindawi}

Submit your manuscripts at

http://www.hindawi.com
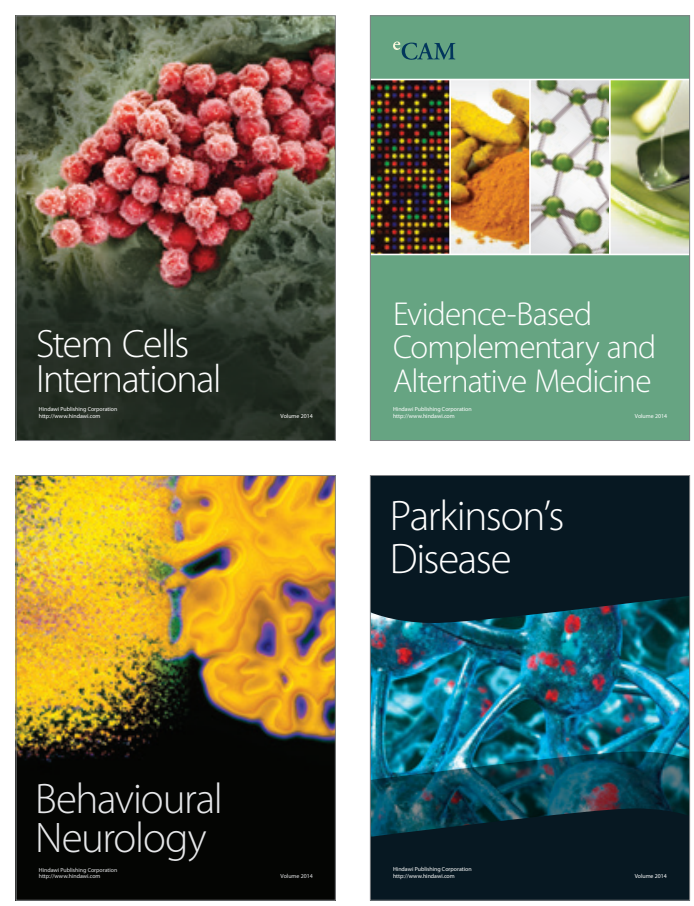

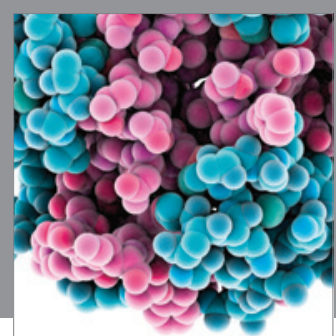

Journal of
Diabetes Research

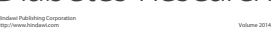

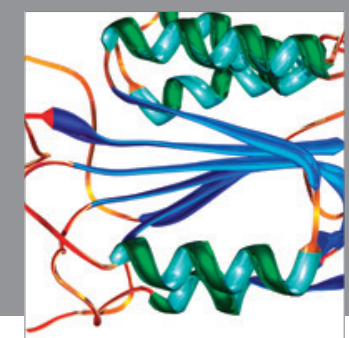

Disease Markers
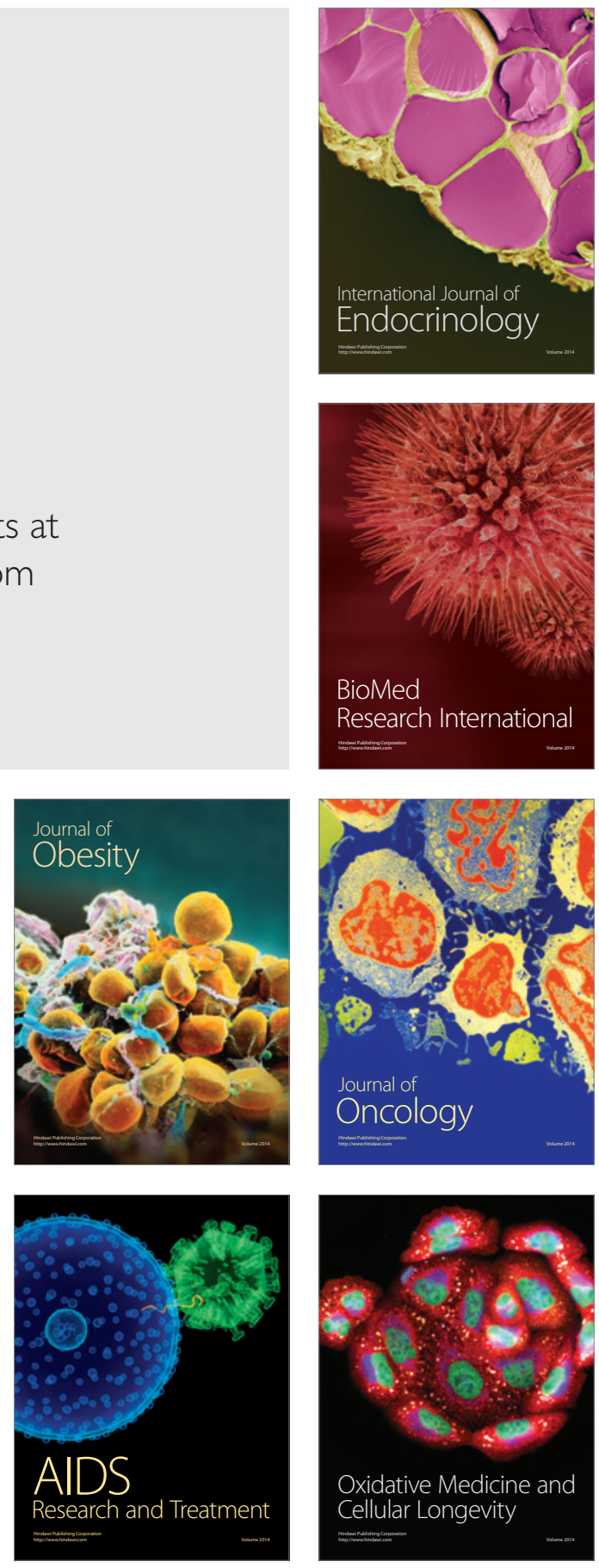